\title{
PROPERTIES OF MOLDINGS PREPARED FROM LDPE-PUMPKIN SEED HULLS BLEND
}

\author{
Karolina Głogowska', Janusz Sikora', Ludmila Dulebova
}

1 Lublin University of Technology, Mechanical Engineering Faculty, Department of Technology and Polymer Processing, 36 Nadbystrzycka St., 20-533 Lublin, Poland, e-mail: k.glogowska@pollub.pl, janusz.sikora@ pollub.pl

2 Technical University in Košice, Department Technologies and Materials, Faculty of Mechanical Engineering, 74 Mäsiarska St., 04001 Košice, Slovakia, e-mail: ludmila.dulebova@tuke.sk

Received: 2017.09.06

Accepted: 2017.11.01

Published: 2017.12.05

\begin{abstract}
In recent decades, standard polymer blends for different applications have been more and more often replaced by blends containing raw materials. The use of natural materials as filler in thermoplastics brings both economic and environmental benefits. The use of a given vegetable filler depends on the geographic location and natural occurrence of the vegetables in a given geographic region. In Poland, for instance, the pumpkin is one of such vegetables. They are used for producing oil which is pressed from pumpkin seeds. Pumpkin seeds are then collected, dried and purified to produce waste material in hull form. Particles of ground pumpkin seed hulls with varying sizes and weight-in-weight concentration ranging from $0 \%$ to $20 \%$ relative to the matrix are used as filler in low-density polyethylene. Pumpkin seed hulls are ground and sieved. Four fractions of hulls with different particle sizes are produced: $<0.2 \mathrm{~mm}, 0.2-0.4 \mathrm{~mm}, 0.4-0.6 \mathrm{~mm}, 0.6-0.8 \mathrm{~mm}$. The paper reports the results of investigation of the mechanical properties, i.e., strength properties determined by static tensile testing and hardness measurement, of injection molds produced at constant processing parameters. In addition, the cross sections of the obtained products are subjected to microscopic examination. Relationships are determined between tensile modulus, maximum tensile stress, tensile stress at yield, maximum tensile strain, tensile strain at yield as well as Shore hardness and weigh-in-weight concentration of the powdered natural filler and its grain sizes. Finally, relevant conclusions are drawn.
\end{abstract}

Keywords: natural filler, low-density polyethylene, pumpkin seed hulls, injection molding.

\section{INTRODUCTION}

Fillers are among basic constituents added to polymeric material to shape its functional properties as desired and reduce the price of material $[1,2,3]$. Although fillers are generally difficult to dissolve in water and they do not dissolve in polymers, they can be uniformly distributed in a liquid or plasticized polymer by means of mechanical mixing $[4,5]$. Generally, in polymer blends, powdered filler particles are a disperse phase while a polymeric matrix is a continuous phase [6]. Interactions between the polymer matrix and the filler play a significant role in the shaping of all properties of such blends. The characteristics of a filler in polymeric matrix such as the distribution of its grain size, its active surface area, degree of fineness, as well as the grain length to grain diameter ratio have impact on the properties of products [6] which are usually formed by extrusion molding or injection molding $[7,8,9]$. The literature reports various kinds of polymer blends in which the polymer is a continuous phase and the powdered filler is a disperse phase $[10,11$, $12]$. In some cases, particularly when their concentration is low, fillers can act as heterogeneous 
nucleates in the polymer crystalline phase [13, 14, 15]. Most polymers are thermodynamically immiscible with one another, and in melt state they form a multiphase system, its structure being dependent on factors such as intermolecular interactions, blend composition and rheological properties of its constituents [16]. To ensure stable properties of such blends, the disperse phase must be uniformly dispersed in the system's matrix (continuous phase), and adhesion between the phases must be sufficiently strong [17].

The aim of this study is to determine the effect of a powdered natural filler on the mechanical properties of a filled polymeric material (LDPE), particularly its basic parameters of strength and variations in these parameters depending on weight-in-weight concentration of the filler and its grain size. In addition to this, the study aims to explain the observed phenomena by examination of the matrix-filler system.

\section{EXPERIMENTAL}

\section{Test stands}

The tests were conducted using a single-screw injection molding machine, marketed under the name of ARBURG ALLROUNDER 320C. The static tensile tests were performed on produced composite molded pieces using a standard Z010 AllroundLine testing machine manufactured by Zwick Roell. Hardness measurements were conducted by the Shore method using the ART.13 hardness tester manufactured by Affri System Hardness Testers. The evaluation of morphology of the specimen cross sections was performed using the Nikon Eclipse LV100ND microscope.

\section{Materials}

The study was conducted using powdered low-density polyethylene, DOWLEX ${ }^{\circledR}$ (LLDPE) 2631.10EU, manufactured by The Dow Chemical Company (Schkopau, Germany). This plastic is used for producing plastic film by blow molding, casting, extrusion molding with coating, rotational casting and injection molding. DOWLEX ${ }^{\circledR}$ is used in many branches of the industry, including the manufacture of industrial, food and medical packaging. Some of its modifications are also used for manufacturing sanitary products, consumer products as well as dairy products. Table 1 lists the properties of the tested polymer after the specifications provided by the manufacturer.
The study involved the use a natural filler in the form of pumpkin seed hulls obtained from a company dealing with purification and sales of pumpkin seeds (Fig. 1a). Mechanical peeling and purification of pumpkin seeds leads to producing a waste material in the form of hulls (Fig. 1b). The main component of pumpkin seed hulls are mixtures of polysaccharide substances (cellulose, hemicellulose, pectin, gum, slime mold) and non-polysaccharide substances (lignin) [18].

\section{Tested parameters}

Given the objective of the study, a set of key parameters were proposed to describe the investigated processes, including injection molding and tensile testing as well as hardness measurements. These parameters were divided into the following groups:

A) Direct response:

- tensile force, $\mathrm{F}_{Z} \mathrm{~N}$,

- yield point, $\mathrm{F}_{\mathrm{R}} \mathrm{N}$,

- change in measuring length at yield $\Delta \mathrm{l}_{\mathrm{R}}, \mathrm{mm}$,

- change in measuring length at maximum tensile force $\Delta \mathrm{l}_{\mathrm{Z}}, \mathrm{mm}$,

- specimen size.

B) Indirect response:

- specimen cross-sectional area $\mathrm{A}, \mathrm{mm}^{2}$, C) Resulting response:

- tensile modulus E, MPa,

- maximum tensile stress $\sigma_{\mathrm{z}}, \mathrm{MPa}$,

- tensile stress at yield $\sigma_{\mathrm{r}}, \mathrm{MPa}$,

- tensile strain $\varepsilon_{z}, \%$,

- tensile strain at yield, $\varepsilon_{\mathrm{r}} \%$,

- hardness $\mathrm{H},{ }^{\circ} \mathrm{ShD}$,

D) Direct factors:

- diameter of filler grain: $<0.2 \mathrm{~mm} ; 0.2 \div 0.4$ $\mathrm{mm} ; 0.4 \div 0.6 \mathrm{~mm} ; 0.6 \div 0.8 \mathrm{~mm}$,

Table 1. Basic properties of the polymer used in the tests

\begin{tabular}{|l|c|}
\hline \multicolumn{1}{|c|}{ Property } & Value \\
\hline Density $\left(23^{\circ} \mathrm{C}\right), \mathrm{kg} / \mathrm{m}^{3}$ & 935 \\
\hline Melt mass flow rate $\left(230^{\circ} \mathrm{C} ; 2.6 \mathrm{~kg}\right), \mathrm{g} / 10 \mathrm{~min}$ & 7 \\
\hline Tensile stress at yield, $\mathrm{MPa}$ & 17.8 \\
\hline Tensile strain at yield \% & 419 \\
\hline Shore hardness, ${ }^{\circ} \mathrm{Sh} \mathrm{D}$ & 56 \\
\hline $\mathrm{HDT}$ temperature, $\mathrm{B}(0.45 \mathrm{MPa}){ }^{\circ} \mathrm{C}$ & 52 \\
\hline $\begin{array}{l}\text { Vicat softening temperature }\left(\mathrm{A} 120 \quad\left(120^{\circ} \mathrm{C} / \mathrm{h}\right.\right. \\
10 \mathrm{~N}),{ }^{\circ} \mathrm{C}\end{array}$ & 115 \\
\hline Melting point, ${ }^{\circ} \mathrm{C}$ & 124 \\
\hline
\end{tabular}



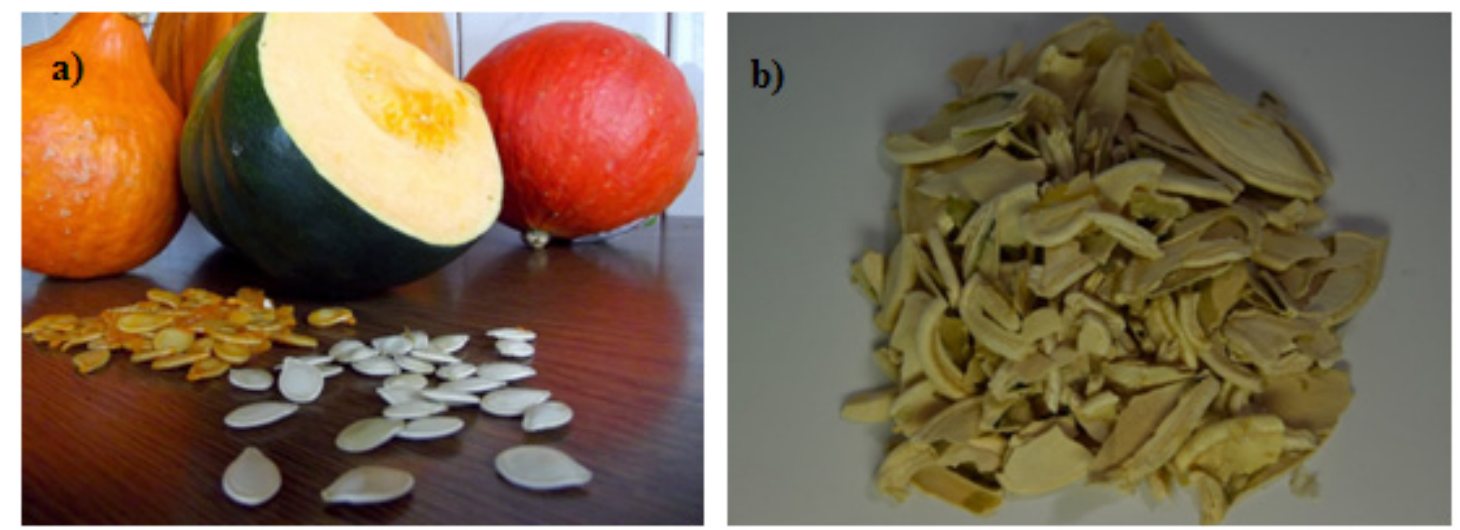

Fig. 1. General view of: a) pumpkins and pumpkin seeds and b) pumpkin seed hulls

- filler weight-in-weight concentrations in specimen: 5, 10, 15 and 20\%,

- polymer temperature $t$ in plasticizing unit of injection molding machine: $130^{\circ} \mathrm{C}, 135^{\circ} \mathrm{C}$, $140^{\circ} \mathrm{C}, 150^{\circ} \mathrm{C}$.

E) Constant factors:

- injection mold temperature, $\mathrm{t}_{\mathrm{f}}=30^{\circ} \mathrm{C}$,

- injection pressure, $\mathrm{p}=10 \mathrm{MPa}$,

- time of polymer injection into closed mold cavity, $\mathrm{T}_{\mathrm{w}}=2 \mathrm{~s}$,

- time of polymer plasticization in plasticizing unit, $\mathrm{T}_{\mathrm{u}}=4 \mathrm{~s}$,

- polymer cooling time in closed mold cavity, $\mathrm{T}_{\mathrm{c}}=20 \mathrm{~s}$,

- specimen tension time, $\mathrm{v}=100 \mathrm{~mm} / \mathrm{min}$.
F) Disturbing factors:

- electric voltage: $219 \div 241 \mathrm{~V}$,

- relative air humidity: $55 \div 65 \%$,

- ambient temperature: $20 \div 24^{\circ} \mathrm{C}$.

The study mechanical properties demonstrated that the disturbing parameters have a negligible effect on the results of the measurements, and can thus be omitted in the results discussion.

\section{METHODS}

As for the preparation of pumpkin seed hulls, they were ground up to powder form and fractions with different grain sizes were separated by means of sieves with the following mesh sizes: $0.2 \mathrm{~mm}, 0.4 \mathrm{~mm} 0.6 \mathrm{~mm}$ and $0.8 \mathrm{~mm}$. As a re-
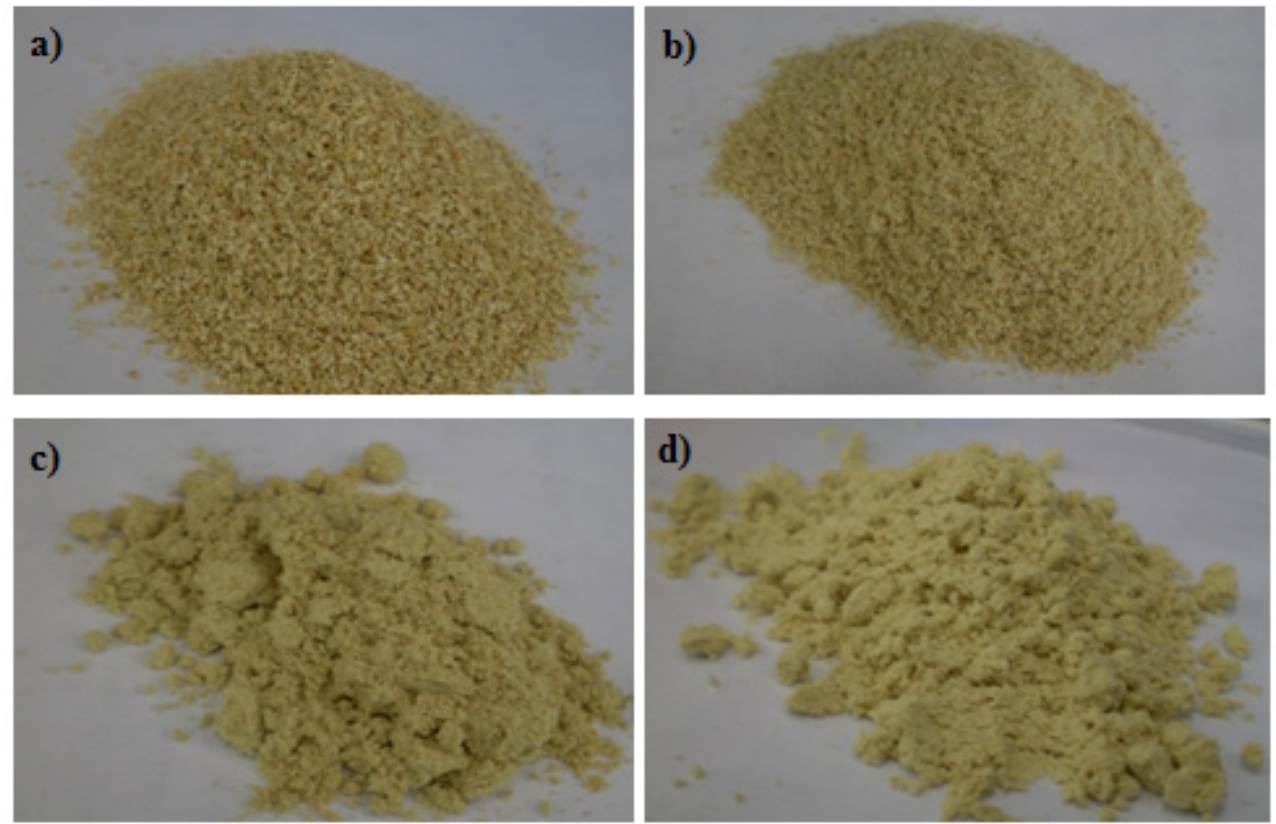

Fig. 2. Produced fractions of ground pumpkin seed hulls with the following grain sizes: a) $0.8 \div 0.6 \mathrm{~mm}$, b) $0.6 \div 0.4 \mathrm{~mm}$ c) $0.6 \div 0.2 \mathrm{~mm}$ and d) $<0.2 \mathrm{~mm}$ 
sult, four fractions were produced, their grain sizes being: $<0.2 \mathrm{~mm}, 0.2 \div 0.4 \mathrm{~mm}, 0.4 \div 0.6 \mathrm{~mm}$, $0.6 \div 0.8 \mathrm{~mm}$. The obtained fractions are shown in Figure 2.

Prior to starting the injection molding machine, the low-density polyethylene and the filler were mixed in a suitable ratio. $360 \mathrm{~g}$ polymer was mixed with the tested content of the powdered filler containing an adhesion promoter in the form of carbofunctional silane, marketed under the name of aminopropyltriethoxysilane.

The materials were mixed, and the mixture was fed into the hopper of the injection molding machine. Then, 10 cycles of the injection molding process were run. Injection molded pieces produced during these cycles were rejected. Successive molded pieces, however, were used as test specimens. The injection molding process was continued until the plasticizing unit of the machine was completely empty. After that, the hopper was loaded with another dose of the prepared mixture, with a different filler content and grain size.

Static tensile tests were performed using the testing machine in compliance with the ISO 5271:1998 standard [19].

Hardness measurements were conducted in accordance with the procedure described in the ISO 527-1:2012 standard [20].

\section{RESULTS AND DISCUSSION}

\section{Strength tests of produced injection molded pieces}

The results of static tensile tests served for drawing diagrams illustrating relationships between the tensile modulus E, maximum tensile stress, tensile stress at yield, strain at maximum tensile stress and strain at yield and the natural filler contents in produced injection molded pieces. The above relationships are shown in Tables $2 \div 7$.

The relationships between tensile modulus $\mathrm{E}$ and filler grain sizes and filler contents are illustrated in Table 2. The addition of a small amount of the powdered natural filler to low-density polyethylene leads to an increase in tensile modulus with increasing the contents of the tested four filler fractions. The highest increase in tensile modulus was obtained for the specimens with $20 \%$ filler content and the grain size range $0.6-0.8$ $\mathrm{mm}$. Compared to unfilled low-density polyethyl- ene, the tensile modulus increased by $116 \mathrm{MPa}$, i.e., by $31.69 \%$. As for three other polymer blends filled with ground pumpkin seed hulls, their tensile modulus also increased, the highest value was obtained for the specimens with $20 \%$ filler content - it increased by $26.63 \%(0.4 \div 0.6 \mathrm{~mm})$, $15.71 \%(0.2 \div 0.4 \mathrm{~mm})$ and $6.55 \%(<0.2 \mathrm{~mm})$, respectively. This means that polymer rigidity has increased, which probably results from constraining movement of polymer chains due to the presence of the natural filler [21]. Another crucial aspect here is the size of grains on the the LDPE matrix-filler grain surface interface the bigger the filler grain size is, the higher the tensile modulus E can be observed.

Table 3 shows the relationship between the maximum tensile stress and filler contents and grain sizes. The addition of powdered pumpkin seed hulls to low-density polyethylene leads to a decrease in the maximum tensile stress in the entire tested range of filler contents. Following the addition of $20 \%$ filler with the grain size $<0.2$ $\mathrm{mm}$, the maximum tensile stress decreases by $11.48 \mathrm{MPa}$, i.e., by $14 \%$. This probably is due to the fact that the matrix is made of a polyolefin polymer, which leads to the weakening of adhesion of hydrophilic pumpkin seed hulls to the hydrophobic polymer matrix. Most natural fillers have a structure which promotes increased water absorption, which changes mechanical properties of polymer. A similar trend was reported in other studies investigating the effect of various natural fillers, such as rice bran, corn and potato starch, on the mechanical properties of polymer compositions $[22,23]$.

Table 4 illustrates the relationship between tensile stress at yield of the filled specimens and filler contents and grain size. The tensile stress at yield of the initial low-density polyethylene is $16.4 \mathrm{MPa}$; on the addition of $5 \%$ natural filler with the grain size ranging from $0.6 \mathrm{~mm}$ to $0.8 \mathrm{~mm}$, the tensile stress at yield first decreases to $4.96 \mathrm{MPa}$ (by $69.72 \%$ ), increasing afterwards. The other three fractions of the filler in the form of ground pumpkin seed hulls exhibit a decrease in the tensile stress at yield; for the specimens with $10 \%$ filler content, the tensile stress decreases by $48 \%$ (0.4 $\div 0.6 \mathrm{~mm}), 50.79 \%(0.2 \div 0.4 \mathrm{~mm})$ and $49.81 \%$ $(<0.2 \mathrm{~mm})$ of the initial value, respectively. The decrease in the tensile stress at yield may be caused by loss of adhesion between the small particles of pumpkin seed hulls and the polymer matrix. The adhesion on the polymer-filler interface 
Table 2. Tensile modulus E versus filler content and grain size

\begin{tabular}{|c|c|c|c|c|c|}
\hline \multirow{2}{*}{ Grain size $[\mathrm{mm}]$} & \multicolumn{5}{|c|}{ Young's modulus E, MPa } \\
\cline { 2 - 5 } & $0 \%$ & $5 \%$ & $10 \%$ & $15 \%$ & $20 \%$ \\
\hline \multirow{3}{*}{$* 0,2$} & 370 & 379 & 386 & 390 \\
\hline $0,2 \div 0,4$ & 366 & 367,5 & 395,5 & 404 & 423,5 \\
\hline \multirow{2}{*}{$0,4 \div 0,6$} & 370 & 401 & 427 & 463,5 \\
\hline $0,6 \div 0,8$ & & 381 & 415,5 & 466 & 482 \\
\hline
\end{tabular}

Table 3. Maximum tensile stress versus filler content and grain size

\begin{tabular}{|c|c|c|c|c|c|}
\hline \multirow{2}{*}{ Grain size [mm] } & \multicolumn{5}{|c|}{ Maximum tensile stress, $\mathrm{MPa}$} \\
\hline & $0 \%$ & $5 \%$ & $10 \%$ & $15 \%$ & $20 \%$ \\
\hline$<0,2$ & \multirow{4}{*}{13,35} & 12,6 & 12,25 & 11,65 & 11,48 \\
\hline $0,2 \div 0,4$ & & 12,65 & 12,4 & 11,85 & 11,6 \\
\hline $0,4 \div 0,6$ & & 12,7 & 12,35 & 12 & 11,95 \\
\hline $0,6 \div 0,8$ & & 12,85 & 12,6 & 12,6 & 12 \\
\hline
\end{tabular}

Table 4. Tensile stress at yield stress versus filler content and grain size

\begin{tabular}{|c|c|c|c|c|c|}
\hline \multirow{2}{*}{ Grain size [mm] } & \multicolumn{5}{|c|}{ Tensile stress at yield, MPA } \\
\cline { 3 - 5 } & $0 \%$ & $5 \%$ & $10 \%$ & $15 \%$ & $20 \%$ \\
\hline \multirow{3}{*}{$<0,2$} & 11 & 8,23 & 9,75 & 11 \\
\hline \multirow{3}{*}{16,4} & 10,8 & 8,07 & 9,66 & 10,1 \\
\cline { 3 - 5 } & & 9,57 & 8,52 & 9,46 & 10,1 \\
\hline $0,4 \div 0,6$ & 4,96 & 8,28 & 8,31 & 8,59 \\
\hline $0,6 \div 0,8$ & & &
\end{tabular}

Table 5. Strain at maximum tensile stress versus filler content and grain size

\begin{tabular}{|c|c|c|c|c|c|}
\hline \multirow{2}{*}{ Grain size $[\mathrm{mm}]$} & \multicolumn{5}{|c|}{ Strain at maximum tensile stress, $\%$} \\
\hline & $0 \%$ & $5 \%$ & $10 \%$ & $15 \%$ & $20 \%$ \\
\hline$<0,2$ & \multirow{4}{*}{13} & 14 & 14 & 12,5 & 10,5 \\
\hline $0,2 \div 0,4$ & & 14 & 13 & 12 & 9,7 \\
\hline $0,4 \div 0,6$ & & 12,5 & 11 & 9,4 & 8,25 \\
\hline $0,6 \div 0,8$ & & 13 & 12 & 9,85 & 9,15 \\
\hline
\end{tabular}

Table 6. Tensile strain at yield versus filler content and grain size

\begin{tabular}{|c|c|c|c|c|c|}
\hline \multirow{2}{*}{ Grain size $[\mathrm{mm}]$} & \multicolumn{5}{|c|}{ Tensile strain at yield, \% } \\
\cline { 2 - 5 } & $0 \%$ & $5 \%$ & $10 \%$ & $15 \%$ & $20 \%$ \\
\hline \multirow{3}{*}{$* 0,2$} & 335 & 87,5 & 36 & 19 \\
\hline \multirow{3}{*}{435} & 265 & 63,5 & 25 & 17,5 \\
\hline \multirow{2}{*}{$0,2 \div 0,4$} & 98 & 37,5 & 17,5 & 13,5 \\
\hline & & 39,5 & 27,5 & 15,5 & 12 \\
\hline $0,6 \div 0,8$ & & &
\end{tabular}

is significant and often has a decisive impact on properties of polymer blends. Polymer adhesion depends on the conditions of polymer absorption on filler surface, filler grain wettability by polymer melt, and bonds created between filler and polymer [24].

Table 5 illustrates the relationship between strain at maximum tensile stress and the applied contents of the filler in the form of powder made of ground pumpkin seed hulls. The blends of low-density polyethylene with $5 \%$ and $10 \%$ of the filler, its grain sizes ranging $0.2 \div 0.4 \mathrm{~mm}$ and $<0.2 \mathrm{~mm}$, show a $7.6 \%$ increase and a decrease in strain at maximum tensile stress, respectively. The diagram reveals that the polymer blend contain- ing the filler with the grain size ranging $0.4 \mathrm{~mm}-$ $0.6 \mathrm{~mm}$ exhibits the highest decrease in strain at maximum tensile stress in the entire tested range of filler content. Compared to unfilled LDPE, its value decreased by $26.92 \%$.

Relationships between tensile strain at yield of filled specimens versus weight-in-weight concentration and grain size of the filler are shown in Table 6 . The relationships point to a falling tendency when compared to the initial low-density polyethylene. The highest tensile strain at yield, 335\%, was obtained for the polymer composition containing 5\% filler with the grain size $<0.2 \mathrm{~mm}$, and its value was lower than that of unfilled LDPE by $16.25 \%$. With increas- 
ing the filler content in other fractions with varying sizes of pumpkin seed hulls, this parameter decreased. Moreover, it can be observed that the bigger the grain size of the natural filler is, the lower the tensile strain at yield can be observed. The addition of $20 \%$ natural filler with the grain size ranging $0.6 \mathrm{~mm}-0.8 \mathrm{~mm}$ led to a decrease in this parameter by $97.24 \%$ compared to the unfilled polymer. This results from a higher rigidity of the material, as proved by a higher tensile modulus of the examined polymer blends.

\section{Hardness of injection moldings}

To determine the effect of natural filler contents and its grain sizes on the hardness of produced injection molds, measurements of Shore $\mathrm{D}$ hardness were made. The hardness results are shown in Figure 3 as a relationship between hardness expressed in the Shore D scale versus filler content and filler grain size.

The hardness of the examined injection molded pieces increases with increasing the pow-

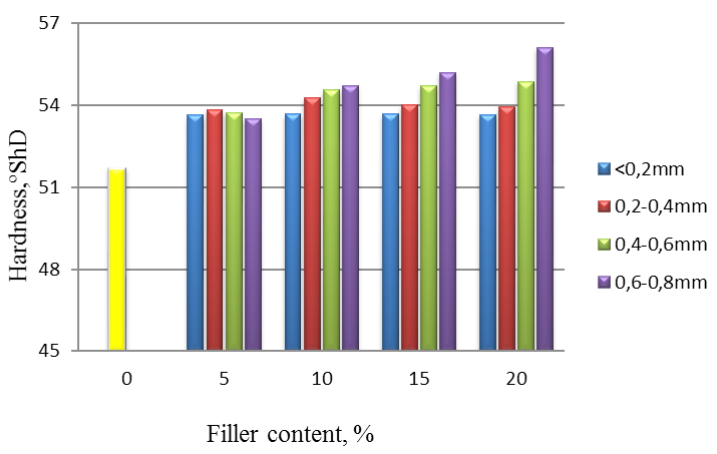

Fig. 3. Hardness $\mathrm{H}$ of the injection molds determined by the Shore method versus filler content and filler grain size

dered filler content, irrespective of filler type. The highest increase in hardness was obtained for the specimens with $20 \%$ content of the natural filler with the grain size ranging $0.6 \div 0.8 \mathrm{~mm}$; here, the hardness increased by $8.61 \%$, which corresponds to an increase in hardness by $4.45^{\circ} \mathrm{ShD}$ compared to that of unfilled LDPE. Examining the diagram,
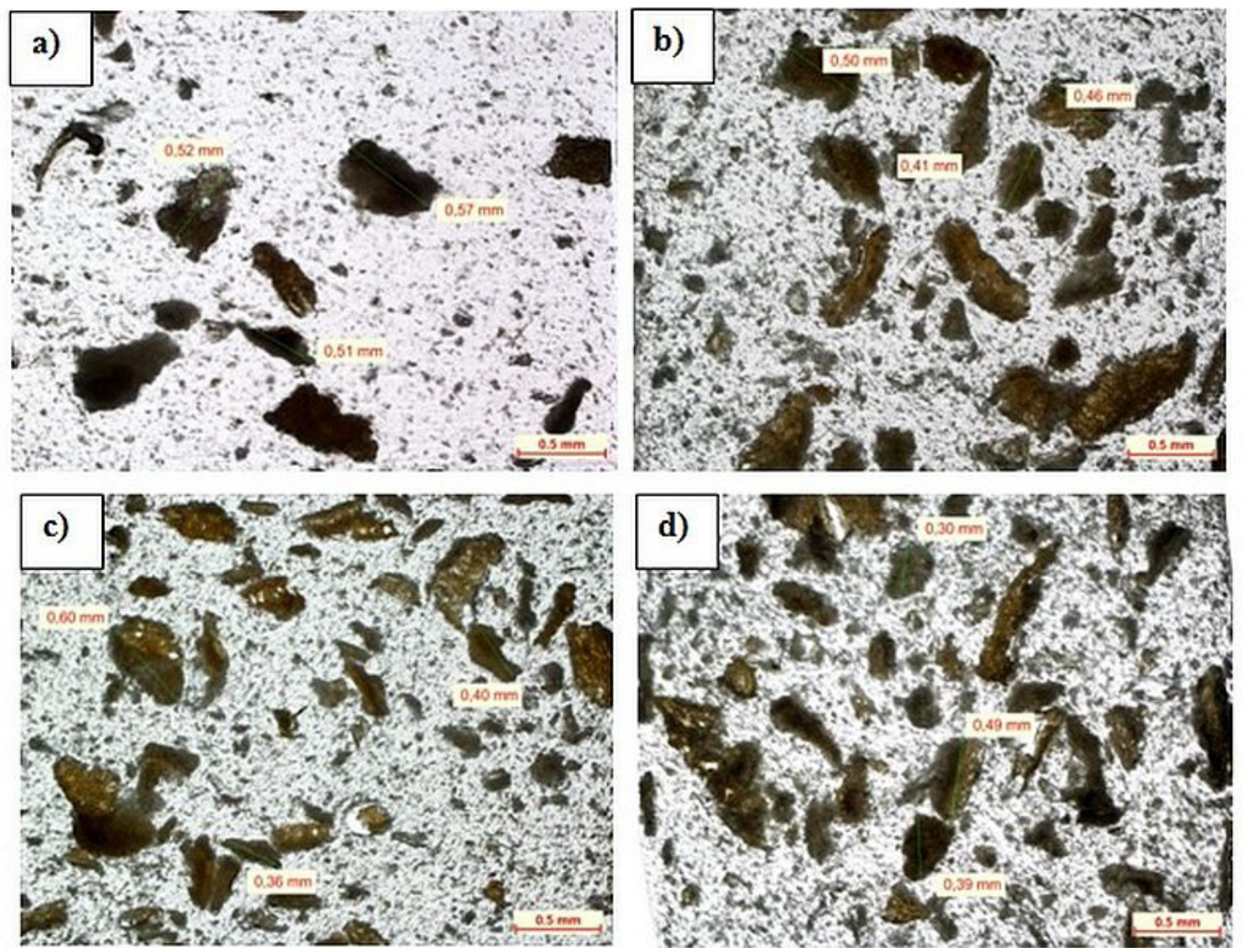

Fig. 4. Cross-section of the tested polymer compositions filled with pumpkin seed hulls with grain size ranging 0.6-0.4 mm: a) LDPE + 5\% natural filler; b) LDPE + 10\% natural filler; c) LDPE + 15\% filler; d) LDPE + 20\% natural filler 
it should be observed that the applied grain sizes and filler contents exert a significant effect on the hardness of polymer blends.

\section{Morphology of produced polymer compositions}

This study involved microscopic examination of the cross section of the produced polymer compositions containing 5, 10, 15 and $20 \%$ of the filler. Images of the morphology in the cross section of the tested injection molded pieces are shown in Fig. 4.

The examination of the morphology reveals a non-uniform distribution of the added natural filler. One can observe the presence of agglomerates and particles of varying sizes. The micrometric particles of pumpkin seed hulls, the surface energy of which is probably higher than that of low-density polyethylene, show a tendency to form agglomerates (Figs. 4b, 4c. and 4d). This is undesired because the filler-polymer contact surface decreases, which leads to reduced adhesion.

The examination of the photographs also reveals that the grains of ground pumpkin seed hulls do not have uniform shape or dimensions, which probably results from the very shape of pumpkin seed hulls and their mechanical properties. Formed by mechanical grinding, the particles have the shape of a plate, its one dimension sometimes exceeding the range applied in the tests. This proves that the polymer blend must be thoroughly mixed in order to produce its uniform structure, and thus properties.

\section{CONCLUSIONS}

The modification of plastics by various kinds of fillers affects both the processing process and mechanical properties as well as morphology of the products. Investigation of changes in properties of thereby modified plastics is significant from the point of view of application possibilities for a given polymer blend.

The investigation of the properties of a blend of low-density polyethylene with ground pumpkin seed hulls led to the following conclusions. With increasing the filler content and grain size, the tensile modulus of the specimens increases while their tensile strength decreases.

The addition of $5 \%$ of the natural filler with the grain size ranging from $0.6 \mathrm{~mm}$ to $0.8 \mathrm{~mm}$ leads to a decrease in the tensile stress at yield of the specimens, when compared to its initial value, i.e., without the filler.

The strain at maximum tensile stress of the tested injection molded pieces increases with increasing the powdered filler content to $5 \%$, only to decrease afterwards. The specimens exhibit a smaller strain at yield than the unfilled ones.

The hardness of injection molded pieces with different contents of the tested natural filler is higher than that of the unfilled polymer. The highest hardness was obtained for the specimens containing $20 \%$ natural filler with its grain size ranging between $0.6 \mathrm{~mm}$ and $0.8 \mathrm{~mm}$.

The optical microscopy examination of the morphology of cross sections of the specimens reveals a non-uniform distribution of the filler in the polymer. The produced polymer blends with different weight-in-weight concentrations of the natural filler show a tendency of filler particles to form agglomerates.

\section{REFERENCES}

1. Shenoy A. V.: Rheology of filled polymer systems. Springer Science \& Business Media, 2013.

2. Klepka T., Jeziórska R., Szadkowska A.: Cienkościenne wyroby z modyfikowanego polietylenu dużej gęstości. Przemysł Chemiczny, 8, 2015, 1352-1355.

3. Strong A. Brent.: Fundamentals of composites manufacturing: materials, methods and applications. Society of Manufacturing Engineers, 2008.

4. Hornsby P. R.: Rheology, compounding and processing of filled thermoplastics. Mineral fillers in thermoplastics I. Advances in Polymer Science, 139, 1999, 155-217.

5. Xanthos, M.: Functional fillers for plastics. John Wiley \& Sons, 2010.

6. Alonso M., Velasco J. I.: Constrained crystallization and activity of filler in surface modified talc polypropylene composite, European Polymer Journal, 33(3), 1997, 255-262.

7. Sikora J. W.: Effect the feed section groove taper angle on the performance of a single-screw extruder, Polymer Engineering and Science, 41(9), 2001, 1636-1643.

8. Samujło B., Sikora J. W.: The impact of selected granulometric properties of poly (vinyl chloride) on the effectiveness of the extrusion process, Journal of Polymer Engineering 2013, 33(1), 2013, 77-85.

9. Głogowska K., Sikora J.W., Duleba B.: Effect of mechanical properties of metal powder-filled hybrid moulded products, Journal of Polymer Engineering, 36(7), 2016, 705-712. 
10. Sterzyński, T.: Processing and property improvement in isotactic polypropylene by heterogeneous nucleation, Polimery, 45, 2000 786-791.

11. Jachowicz T., Dulebova L.: Badania zawartości napełniacza mineralnego na charakterystykę $p$ v-T polipropylenu. Przemysł Chemiczny. 12, 2015,2295-2298.

12. Work W.J., Horie K., Hess M., Stepto R.F.T.: Defnition of terms related to polymer blends, composites and multiphase polymeric materials. Pure and Applied Chemistry, 76, 2004, 1985-2007

13. Sterzynski, T., Calo P., Lambla, M., Thomas, M.: Trans and Dimethyl quinacridone nucleation of isotactic polypropylene, Polymer Engineering \& Science, 37(12), 1997, 1917-1927.

14. Sterzyński T.: Processing and property improvement in isotactic polypropylene by heterogeneous nucleation. Polimery, 45(11-12), 2000, 786-791.

15. Gahleitner, M.: Melt rheology of polyolefins. Progress in polymer science, 26(6), 2001, 895-944.

16. Suh C. H., White J. L.: Talc-thermoplastic compounds: particle orientation in flow and rheological properties. Journal of non-newtonian fluid mechanics, 62(2), 1996, 175-206.

17. Dulebova L., Garbacz T.: The effect of particulate illers on hardness of polymer composite. Advances In Science And Technology Research Journal.
3(211), 2017, 66-71.

18. Zheng X., et al.: Effect of process parameters of microwave assisted extraction (MAE) on polysaccharides yield from pumpkin. Journal of Northeast Agricultural University, 2011, 18(2), 79-86.

19. ISO 527-1:2012 Plastics - Determination of tensile properties - Part 1: General principles.

20. ISO 868:2005. Plastics and ebonite - Determination of indentation hardness by mean of a durometer (Shore hardness).

21. Rothon R.: Mineral Fillers in Thermoplastics: Filler Manufacture and Characterisation. Advances in Polymer Science, 139, 1999, 67-107.

22. Żenkiewicz M., Richert J.: Influence of polymer samples preparation procedure on their mechanical properties. Journal of Achievements in Materials and Manufacturing Engineering 26, 2, 2008, 155-158.

23. George J., Kumar R. and others: Rice bran-filled biodegradable low-density polyethylene films: Development and characterization for packaging applications. Journal of Applied Polymer Science, 5, 2006, 4514-4522.

24. Nuraya A. S., Baharin A., Azura A. R.: Influence of banana stem powder on knotty tear behaviour of prevulcanised natural rubber latex composite films. Plastics, Rubber and Composites: Macromolecular Engineering, 44, 2015, 265-272. 